\title{
DIDÁTICA E FORMAÇÃO INICIAL DO PROFESSOR: DESAFIOS E PERSPECTIVAS NA VISÃO DOS ACADÊMICOS DO CURSO DE PEDAGOGIA DE UMA INSTITUIÇÃO DE ENSINO SUPERIOR (IES) DO MUNICÍPIO DE PARINTINS-AM
}

\author{
DIDÁCTICA Y FORMACIÓN INICIAL DEL PROFESORADO: RETOS Y \\ PERSPECTIVAS DESDE LA MIRADA DE LOS ALUMNOS DEL CURSO DE \\ PEDAGOGÍA DE UNA INSTITUCIÓN DE ENSEÑANZA SUPERIOR (IES) DEL \\ MUNICIPIO DE PARINTINS-AM
}

\author{
DIDACTICS AND INITIAL TEACHER EDUCATION: CHALLENGES AND \\ PERSPECTIVES IN THE VIEW OF STUDENTS OF THE PEDAGOGY COURSE OF \\ AN HIGHER EDUCATION INSTITUTION (IES) IN THE MUNICIPALITY OF \\ PARINTINS-AM
}

\author{
Evandro Luiz GHEDIN ${ }^{1}$ \\ Carlos César Macêdo MACIEL ${ }^{2}$ \\ Artemison Montanho da SILVA ${ }^{3}$
}

RESUMO: O presente artigo objetiva examinar sistematicamente a disciplina Didática I na formação inicial docente do curso de Pedagogia de uma IES do município de Parintins-AM, concernente à prática do professor; problematizando a referida matéria como orientada ao processo formativo desse profissional da educação. Trata-se de um trabalho de natureza qualitativa, com foco nos registros dos acadêmicos, oriundos da autoavaliação da disciplina supracitada. $\mathrm{O}$ arcabouço teórico desta pesquisa abrange principalmente os trabalhos de Alarcão (2016), Candau (2014), Libâneo (2013), entre outros estudiosos de notável envergadura acadêmica sobre a temática investigada. Os resultados evidenciam que a Didática oportuniza aos licenciandos o entendimento das circunstâncias de aprendizagens, partindo da prática social questionada, apoiado no conhecimento de mundo dos professores e dos estudantes da educação básica.

PALAVRAS-CHAVE: Formação inicial. Didática. Perspectivas. Desafios. Parintins.

RESUMEN: Este artículo tiene como objetivo examinar sistemáticamente la asignatura Didáctica I en la formación inicial del profesorado de la carrera de Pedagogía de una IES del municipio de Parintins-AM, en torno a la práctica docente; problematizando la dicha asignatura como orientada al proceso de formación de este profesional de la educación. Se trata de un estudio cualitativo, con enfoque en expedientes académicos, que surge de la

${ }^{1}$ Universidade Federal do Amazonas (UFAM), Manaus - AM - Brasil. Professor Titular-Livre da Faculdade de Educação. Doutorado em Educação (USP). ORCID: https://orcid.org/0000-0002-2844-6122. E-mail: evandroghedin@gmail.com

${ }^{2}$ Universidade Federal do Amazonas (UFAM), Manaus - AM - Brasil. Doutorando no Programa de PósGraduação em Educação. ORCID: https://orcid.org/0000-0002-6722-6712. E-mail: carlosmacielufam@gmail.com

${ }^{3}$ Universidade Federal do Amazonas (UFAM), Manaus - AM - Brasil. Mestrando no Programa de PósGraduação em Educação. ORCID: https://orcid.org/0000-0003-3263-0034. E-mail: artemisonsilva@gmail.com 
autoevaluación de la asignatura citada. El marco teórico de esta investigación cubre principalmente los trabajos de Alarcão (2016), Candau (2014), Libâneo (2013), entre otros estudiosos de notable alcance académico sobre el tema investigado. Los resultados muestran que la Didáctica brinda a los estudiantes de pregrado una comprensión de las circunstancias de aprendizaje, a partir de la práctica social cuestionada, sustentada en el conocimiento del mundo de los docentes y estudiantes de educación básica.

PALABRAS CLAVE: Formación inicial. Didácticas. Perspectivas. Retos. Parintins.

ABSTRACT: This article aims to systematically examine the Didactics I discipline in the initial teacher training of the Pedagogy course of an HEI in the municipality of Parintins-AM, concerning the teacher's practice; problematizing the referred matter as oriented to the training process of this education professional. This is a qualitative study, with a focus on academic records, arising from the self-assessment of the aforementioned discipline. The theoretical framework of this research mainly covers the works of Alarcão (2016), Candau (2014), Libâneo (2013), among other scholars of remarkable academic scope on the subject investigated. The results show that Didactics provide undergraduate students with an understanding of the learning circumstances, based on the questioned social practice, supported by the knowledge of the world of basic education teachers and students.

KEYWORDS: Initial education. Didactics. Perspectives. Challenges. Parintins.

\section{Introdução}

$\mathrm{Na}$ conjuntura educacional brasileira, a formação inicial docente vem sendo o propósito de numerosos debates mediados por eventos na área da educação, como congressos, seminários, simpósios, fóruns etc., os quais abordam esse assunto minuciosamente. Em face dessa realidade, os pesquisadores presumem que a formação necessita colaborar com a profissionalização do professor, objetivando intensificar a regulamentação profissional pela ação e reconhecimento social da categoria, aos quais se unem a valoração da identidade do professor, sem desagregá-la da pessoa e do educador.

Assumindo como parâmetro uma pesquisa empreendida nessa disciplina, no presente artigo pretendemos examinar a Didática na formação inicial docente, almejando entender quais os seus benefícios à formação de professores. Assim, pretendemos responder as seguintes indagações: Quais os contributos da Didática para a formação docente? De que forma os acadêmicos de Pedagogia entendem a relevância da Didática para seu processo formativo enquanto futuros profissionais da educação? Como sistematizar e assimilar a disciplina Didática na prática docente, levando em consideração os parâmetros de formação que buscamos incorporar à conjuntura das licenciaturas, tais como a promoção do comportamento autônomo, criativo, crítico e reflexivo, oriundos de um posicionamento de 
investigador em face da prática? Finalmente, como estimular no acadêmico a compreensão da relevância da docência para sua formação inicial e para o aprimoramento da atuação pedagógica?

\section{Procedimentos metodológicos da pesquisa}

O lócus da pesquisa compreende o curso de Pedagogia de uma IES do município de Parintins, que o oferece há pouco mais de dez anos. No curso, a Didática encontra-se dividida em Fundamentos de Didática, Didática I, Didática na Organização do Trabalho Pedagógico. O cerne da pesquisa reputa os resultados de uma autoavaliação realizada com 35 participantes, todos acadêmicos de Licenciatura Plena em Pedagogia, no cenário da disciplina Didática. $\mathrm{O}$ estudo implicou sobre as aprendizagens e ponderações a respeito do seu processo formativo apresentadas pelos acadêmicos.

O instrumento de coleta de dados se valeu da aproximação teórica da disciplina, compreendendo o vínculo com a ação do professor, o que nos fez fundamentar o processo metodológico na 'Sistematização Coletiva do Conhecimento', onde as práticas, segundo Maniesi (2016) são edificadas coletivamente, e concretizadas na finalidade da ação do professor, onde docentes e estudantes, de forma conjunta, concebem modos de pensamento, sentimento e prática, partindo da ação docente e suas problemáticas.

Ao entender os fundamentos dessa ação, o professor organiza seus conhecimentos, os quais representam começos hodiernos para enfrentar determinadas circunstâncias desta ação. A partir deste momento, em nossos procedimentos buscamos desenvolver a produção textual em duas fases correlacionadas. Primeiramente ponderamos acerca da Formação de Professores, permanentemente localizando a Didática no percurso de formação inicial do pedagogo, doravante, apresentamos os resultados da pesquisa a respeito das contribuições da Didática, igualmente a respeito da metodologia empregada na disciplina, em um panorama de investigação inclusiva onde a pormenorização e crítica a integram (MONFREDINI; MAXIMIANO; LOTFI, 2013).

\section{Didática e a formação inicial do pedagogo}

Como mencionado outrora, a presente pesquisa objetiva analisar a Didática na formação inicial docente com base nas reflexões dos licenciandos a respeito das suas aprendizagens na disciplina de Didática I, a qual visa tornar mais amplo o entendimento dos 
acadêmicos sobre os processos didáticos e sua sistematização pedagógica mediante a Sistematização Coletiva do Conhecimento.

A Sistematização Coletiva do Conhecimento refere-se a uma proposição de aula e de fazer pedagógico fundado em um eixo epistemológico que compreende o estudante enquanto aquele que igualmente conhece, e não apenas o docente, modificando as relações na sala de aula e o comportamento didático. Em outras palavras, considera o posicionamento crítico e reflexivo dos sujeitos, assim como sua capacidade de produção de saberes. Para efetivar essa abordagem, a professora, com base em Libâneo (2013), lançou como proposta quatro etapas didático-pedagógicas: 1) Classificação e questionamento da prática educativa dos participantes; 2) Esclarecimento da prática mediada por um aporte teórico; 3) Entendimento da prática no grau da totalidade, evidenciando suas bases; 4) Formulação de propostas para uma prática docente.

Pretendendo examinar as reflexões dos acadêmicos de Pedagogia sobre a prática experienciada na disciplina de Didática I, ressaltando sua colaboração no processo formativo do estudante, os saberes assimilados e a magnitude imputada a esses saberes, foi realizada uma autoavaliação com uma turma de 30 acadêmicos do curso mencionado. A ferramenta é composta por 3 questões onde na primeira temática é solicitada a elaboração de uma carta para um(a) amigo(a) como convite para participar da disciplina. Consequentemente, é solicitado que apresentem como proposta um plano de aperfeiçoamento de seus saberes e ação docente referente ao campo da Didática. Na questão 3, os acadêmicos elencam 15 temáticas de aprendizagens incentivados por uma listagem a ser classificada de 1 a 10 , onde 10 remete ao tópico de maior relevância e que mais assimilaram, de acordo com as finalidades propostas na disciplina. Nesse tópico encaminha-se uma questão aberta onde é solicitado ao acadêmico a exposição de outras aprendizagens pertinentes à disciplina de Didática I.

Doravante a leitura pormenorizada das respostas às problematizações de autoavaliação, começamos a definir as principais categorias que respaldam os discursos dos acadêmicos, buscando sistematizar as informações e analisá-las. As categorias definidas no início foram: Relevância da didática; Entendimento da didática e de seus componentes; Conjunção teoria e prática; Relação professor/aluno; Abordagens pedagógicas e a prática do professor; Função do educador e da educação na comunidade social. Depois dessa sistematização inicial, efetivamos outra análise e começamos a apontar as interseções entre essas categorias, unindo-as e/ou adicionando-as em subcategorias. Dessa forma, optamos por duas amplas categorias, sendo elas: Entendimento e relevância da Didática e seus componentes (compreensão de Didática e sua relevância na formação docente, assim como a 
compreensão do processo de ensino e aprendizagem com realce para seus componentes); A função do educador e sua prática docente (ênfase para a conjunção teoria e prática, relação professor/aluno, as abordagens pedagógicas e a função docente para a transformação da sociedade).

Essas categorias mostraram-se significativas para revelar a percepção que os acadêmicos conceberam sobre a esfera teórica e prática da Didática, conduzindo-nos, conforme Alarcão (2016), à identificação dos elementos teóricos primordiais ao exame e ação reflexiva que preconizamos suscitar nesse estudo. As categorias, ora mencionadas, abrangem os graus de aprendizagens adquiridos pelos licenciandos na disciplina Didática I, e referem-se às finalidades propostas na disciplina citada.

\section{Entendimento e relevância da didática e seus componentes}

Essa categoria exterioriza a aprendizagem que os acadêmicos obtiveram sobre o 'entendimento' e 'relevância' dos componentes da Didática, tendo em vista o desempenho da prática do professor. Compreendemos que a aprendizagem alcança esse grau de entendimento do saber mediante o envolvimento participativo do acadêmico nesse processo pedagógico, propiciando, com isso, a elaboração e desenvolvimento de novos conhecimentos. Para que isso aconteça, conforme Marin (2019) e Libâneo (2013), não poderemos nos satisfazer somente em pormenorizar ou esclarecer. A superação desses dois graus de saber é a procura do porquê, isto é, do "entendimento", reputado pelos referidos autores como o grau de maior aperfeiçoamento do saber.

Nesse sentido, pudemos identificar que grande parte dos acadêmicos começou a entender as finalidades, conteúdos, procedimentos metodológicos e avaliativos, planejamento, as abordagens pedagógicas, dentre outros conteúdos basilares para a execução da prática educativa do professor, imputando um novo sentido para o conhecimento da Didática no processo formativo docente (ALARCÃO, 2016). Seguem alguns registros apresentados pelos acadêmicos da disciplina Didática I:

[...] Por meio do ensino, a Didática I torna mais compreensível como acontece a prática no ambiente de sala de aula, quais abordagens pedagógicas existem, os diferentes procedimentos metodológicos, modelos de plano de ensino, como o Projeto Político Pedagógico (PPP), que foi o que mais chamou a minha atenção, especialmente por levar em consideração a participação coletiva da comunidade onde a escola está inserida (ACADEMICO 01).

Notei que o planejamento fornece uma maneira de ensinar o conteúdo, para que os professores possam escolher o método de ensino, quais atividades 
planejar e o tempo gasto em cada uma delas, que constitui o cronograma do currículo para proporcionar uma experiência de aprendizado qualitativa e significativa, para alcançar as metas de aprendizado dos estudantes (ACADEMICO 19).

Tais registros expressam o entendimento dos alunos sobre os elementos do processo de ensino envolvidos na prática educativa do professor. Eles destacaram sua importância nesse processo e enfatizaram que o plano era considerado uma ferramenta para organizar o trabalho de ensino.

No tocante à relevância atribuída à Didática, pudemos identificar que uma parcela significativa dos acadêmicos, ao passo que entenderam o campo da Didática, começaram a corroborá-la ao descobrirem sua relevância para o processo formativo docente. A disciplina pormenorizou a docência no pensamento dos licenciandos, ao mesmo tempo em que fomentou uma nova perspectiva sobre o fazer educativo. As respostas oferecidas pelos acadêmicos às questões definiram a Didática enquanto disciplina fundamental na formação inicial do educador e a notaram como adequada na contribuição no aperfeiçoamento da prática do professor.

Identificamos nos escritos dos acadêmicos, ao mostrar a relevância da Didática, menção à eficácia da disciplina em responder às incertezas e questões externadas por determinados acadêmicos sobre o saber didático e sua aplicação no âmbito das instituições de ensino. Esses registros espelham uma preocupação coletiva aos licenciandos, que é a importância de concretizar gerando conhecimentos oriundos da prática no espaço de sala de aula com os saberes advindos do âmbito teórico. Assim, conforme Medeiros e Aguiar (2018) e Libâneo (2013), as licenciaturas, ao seguirem um currículo assentado na indivisibilidade entre prática e teoria, começam a entender a prática, identificando-a. Os seguintes relatos exprimem com mais acuidade nossa observação:

A disciplina Didática nos possibilita mergulhar em um mundo onde podemos questionar e refletir, algo indispensável para a nossa consciência crítica. Claro que possuímos algumas dúvidas sobre o modo de aplicação dessas ideias na escola, o que nos induz à reflexão sobre quais ferramentas metodológicas gostaríamos de empregar nesse percurso (ACADÊMICO 25).

Situada entre as disciplinas destinadas à prática do professor nas licenciaturas, a Didática mostra-se indispensável na compreensão de saberes relativos à docência, uma das estruturas basilares da formação inicial e continuada do educador. Assim, as Diretrizes Curriculares Nacionais, para a formação inicial e continuada do professor em nível superior, reconhecem os elementos e peculiaridades da introdução aos saberes docentes que necessitam 
se expressar nos Projetos Pedagógicos e Curriculares dos Cursos de Formação de Professores e em cursos de formação pedagógicas para licenciandos, seja primeira ou segunda licenciatura. O foco de atenção dessas dimensões encontra-se amplamente direcionado ao campo pedagógico da Didática ao preconizar conhecimentos epistemológicos e pesquisas sistemáticas de conjunturas educacionais, habilidades referentes às metodologias de ensino e ponderações acerca dos processos educacionais e de aprendizagens.

$\mathrm{O}$ Art. $7^{\circ}$ dessas Diretrizes remete-se às dimensões da iniciação à docência, como a compreensão da escola e seu ambiente, planejamento da prática do professor, avaliação do método pedagógico, entendimento dos princípios didáticos, bem como da matriz curricular da instituição de ensino, grandemente observados nos escritos dos acadêmicos da disciplina analisada, quando elucidam, visivelmente, a relevância da Didática na formação inicial do professor.

\section{A prática docente em questão}

Identificamos nesta categoria que os acadêmicos germinam uma perspectiva crítica acerca da prática do professor ao passo que compreendem o docente como agente transformador da sociedade. Com isso, ao se examinar a prática educativa dos educadores nas instituições de ensino que observaram, como proposição da disciplina Didática I, evidencia-se uma contextualização da ação didática que ampare a superação do simples 'repasse de conteúdos', isto é, exprimem inquietação sobre um processo formativo que lhes torne oportuno o desenvolvimento de um 'ser professor' distinto daquele padrão grandemente criticado durante a história da educação.

Nos registros dos estudantes, verificamos o termo Conteúdo, mesmo que em diminuta evidência, seguido pelos termos trabalho, diferente, contextualização, melhores procedimentos metodológicos. Assim, ressaltamos o seguinte registro:

Frequentemente falam sobre deficiências pedagógicas na educação, no entanto, é muito importante descobrir, mesmo diante dos problemas ou demandas obrigatórias que a matriz curricular da escola estabelece, posso afirmar com segurança há a possibilidade de harmonizar a educação com transformação de homens e mulheres (ACADÊMICO 17).

Do mesmo modo, essa declaração foi sublinhada em determinados registros e exterioriza a inquietação supracitada, isto é, almejam sucessivamente o assentamento de um perfil profissional inovador, que leva em consideração a relação dialógica, o compromisso participativo e o pensamento crítico, como asseveram: “essas temáticas nos fazer pensar a 
educação sob outra perspectiva, possibilitando conhecer o conservadorismo, deixando claro como os docentes, em outras épocas, defendiam a disciplina e o autoritarismo como o cerne do processo pedagógico" (ACADÊMICO 7); bem como, "gostei muito de ler sobre o planejamento por projeto, uma vez que ele, em seu desenvolvimento, permeia um tema e busca reunir conjuntamente todas as disciplinas e o interesse dos estudantes e de suas vivências enquanto sujeitos situados em um determinado contexto social" (ACADÊMICO 29).

Portanto, na compreensão dos alunos, a sugestão de método do educador está diretamente relacionada ao conteúdo que ele escolhe usar e sua acepção para o grupo. Em outras palavras, o conteúdo e a forma mudam entre si, porque o conteúdo confere signifícado à forma, que também traz sentido ao conteúdo. De acordo com Candau (2014), quando um professor desenvolve um trabalho de maneira tradicional ou inovadora, ele começa a usar esse método para expressar conteúdo, mas se ele possuir uma criticidade intrínseca, isso dará ao professor um novo significado no método de ensino em sala de aula.

Com base nessa categoria examinada, podemos identificar determinadas subcategorias que se encontram vinculadas ao desempenho didático do profissional da educação. Dentre elas, os registros evidenciam a indivisibilidade entre teoria e prática enquanto condição indispensável ao processo formativo docente. O termo Ação é, igualmente, uma das palavras de maior destaque nos depoimentos dos acadêmicos, acompanhada pelas palavras reflexão, participação, aprendizagem e interesse.

Compreendemos, a partir da leitura das cartas, que a indivisibilidade entre teoria e prática fomentada no contexto da disciplina de Didática mostrou-se perceptível aos estudantes e, para os mesmos, o termo Ação concerne ao reconhecimento da prática enquanto promotora do desenvolvimento pedagógico do sujeito, uma vez que é por meio da ação prática que há a possibilidade de suscitar processos de reflexão, incitando o compromisso participativo e o interesse dos estudantes, tornando a aprendizagem solícita.

Além da conjunção teoria-prática, os licenciandos igualmente consideram a relação professor-aluno enquanto aspecto determinante a ser reputado, por isso a ênfase para dois termos fundamentais ao processo de ensino-aprendizagem: 'Professor e Aluno', vinculandoos às relações e suas inferências no processo pedagógico. Salientamos os trechos consecutivos das cartas: "A relação interativa com a professora ao longo das aulas é contínua, o que oportuniza debates a respeito do o processo pedagógico como um todo" (ACADÊMICO 15); e, também um trecho que exprime a afetividade nas interações com a educadora: “[...] a admirável e eficiente professora que trabalhou conosco essa disciplina, com imenso 
compromisso humano" (ACADÊMICO 27). De acordo com Giancaterino (2018, p. 74), o “processo educacional não é um processo isolado; é constituído conjuntamente por professores e educandos na interação e com vínculo na afetividade, na participação, na cooperação de ambos, construindo-se e acomodando-se, assim, a aprendizagem”.

Ressaltamos que, dos 30 (trinta) licenciandos que fizeram a carta apontando as razões que alegavam para cursar a disciplina de Didática I, somente 7 (sete) não mencionaram a avaliação. Identificamos que a grande parte dos registros consideram a avaliação como promotora dos resultados do desenvolvimento educativo do estudante, expressando, com isso, preocupação com a prática de avaliação, como, do mesmo modo, descobertas que os auxiliaram no reexame das formas e pressuposições que fundamentam o processo avaliativo. Analisemos o que tais registros exprimem:

\begin{abstract}
Além disso, a avaliação é algo que você precisa reconsiderar, porque, como você me disse: 'Realmente faço o exame tradicional', na disciplina Didática, você perceberá que mesmo essa avaliação ainda é muito comum, não é a mais adequada, já pensou em realizar uma avaliação formativa? (ACADÊMICO 26).
\end{abstract}

Descobri que, sobre o dia da avaliação, o que nos preocupava antigamente não precisa persistir nos futuros alunos. Acredite ou não, essa avaliação é muito mais estressante do que no dia em que realizamos o teste horrivel. A avaliação pode ser completamente diferente e até emocionante. Isso pode acontecer durante o processo de aprendizagem e pode ser aplicado de diferentes maneiras. Por exemplo, eu nunca fiz um "exame" como um curso de ensino, o professor é sempre muito criativo (ACADÊMICO 03).

Os registros dos acadêmicos lançam novas perspectivas sobre a avaliação em um esforço de desconstrução de sua percepção da prática tradicional, concentrada apenas no julgamento de alunos 'bons' ou 'ruins', bem como nos resultados da aprendizagem relacionados àqueles que 'mostram interesse em aprender' e aos que 'não querem nada com a vida'. Essa é uma prática que a escola costuma instilar entre os alunos, e a família e a sociedade a fortalecem. Ao longo da prática pedagógica do professor, ela sendo estendida ao seu método de avaliação, percebemos que os acadêmicos começaram a ter essa compreensão participando do processo de aprendizagem fornecido pela disciplina Didática, entendendo que a avaliação é um componente de grande importância desse processo, como mostra o registro a seguir: “[...] nunca imaginei que a avaliação fazia parte do processo educativo [...]. Esse é um ato complexo que exige que nossos profissionais da educação tenham uma perspectiva mais refinada, não apenas uma simples correção para obter julgamentos de valor" (ACADÊMICO 16). Além disso, eles começaram a descobrir que o conhecimento sobre avaliação não apenas 
beneficia quem será professor, mas também favorece aqueles que experimentaram esse processo educacional como aluno. Como mencionado pela seguinte acadêmica: "Mesmo que o objetivo não seja ser professor, aprendê-la apenas enriquecerá seu conhecimento. Afinal, saber como ela foi avaliado e os procedimentos usados pelo professor, ajudará na formação acadêmica e individual” (ACADÊMICO 11).

Dentre as várias compreensões de avaliação que existem, o entendimento dos licenciandos atraiu nossa atenção, indicando que a prática de avaliação experienciada na matéria Didática I fornece, corroborando Alarcão (2015), um novo significado a partir da inserção dos mesmos no processo de aprendizagem, de forma consciente.

Assim, argumentamos que promover condições de ensino e aprendizagem nesse percurso de construção epistemológica oportuniza que docentes e discentes interajam de forma a dialogar e compartilhar conhecimentos de mundo, o que é uma compreensão de todo o processo. Segundo Medeiros e Aguiar (2018), talvez possamos até abandonar gradualmente o termo ensino e manter apenas com o conceito do termo aprendizagem, porque no conceito dialético, os protagonistas de todas as ações educacionais trabalham e aprendem reciprocamente.

Prosseguindo com o exame das informações coletadas na investigação, apresentamos a esquematização das finalidades da matéria Didática I, exibindo os resultados da aprendizagem e o nível de relevância da mencionada matéria demonstrada pelos acadêmicos. Tal questão encontra-se refletida na autoavaliação, aludida em momento anterior, da seguinte maneira: Dos saberes aprendidos na disciplina Didática enumere de 1 a 10 por ordem crescente de relevância (a mais relevante é 10) e que você pondera que mais conhece. Observemos o que cada item de aprendizagem apresenta na esfera da Didática e a pontuação imputada pelos acadêmicos:

a) Abordagens pedagógicas buscando diferenciá-las - 107 pontos;

b) O significado de didática - 105 pontos;

c) Os componentes didáticos: estabelecimento de finalidades, escolha de assuntos curriculares, proposta de metodologias didáticas e avaliativas - 115 pontos;

d) Como examinar a prática de ensino e aprendizagem das instituições escolares - 130 pontos;

e) Como formular um plano de ensino - 90 pontos;

f) Diferenciar os diversos modelos de plano de ensino - 142 pontos;

g) Como estruturar um planejamento de avaliação - 123 pontos; 
h) Como examinar, de forma crítica, um planejamento de avaliação - 107 pontos;

i) Pormenorizar os significados de avaliação - 130 pontos;

j) Contrastar métodos pedagógicos - 112 pontos;

k) Empregar, de maneira adequada, ferramentas pedagógicas - 150 pontos;

1) Trabalho colaborativo em equipe - 114 pontos;

m) Leitura e síntese das produções textuais em didática - 90 pontos;

n) Como examinar e compreender uma produção textual de didática - 80 pontos;

o) Expor propostas didáticas para a prática do professor - 126 pontos.

Conforme o enunciado da questão, os licenciandos marcaram, em ordem crescente, o tópico que julgaram de maior relevância e que tiveram maior aprendizado. Argumentamos, com isso, que os mesmos possuem mais segurança sobre alguns assuntos curriculares do que em outros, exprimindo sua aprendizagem na esfera da Didática. Os resultados indicam que o conteúdo mais compreendido diz respeito a 'Empregar, de maneira adequada, ferramentas pedagógicas', isto é, este tópico refere-se a uma das finalidades da matéria, influenciando, do mesmo modo, sua proposição metodológica que, trabalhando com ferramentas pedagógicas, busca considerar a relação teoria e prática mediante um processo que acontece individual e coletivamente, oportunizando, com isso, o desenvolvimento de novas formas de aprender, com base no relacionamento interativo entre os partícipes desse processo, docente e discente, experienciadas no ambiente escolar. Assim, o futuro profissional da educação entende que os saberes construídos e experienciados em sua formação inicial, além de lhe oportunizar uma aprendizagem considerável, proporciona novas concepções sobre a prática do professor:

Sempre muito cuidadosa, a professora raramente dá aulas expositivas, onde apenas ouvimos as explicações dela. Frequentemente montamos grupos com a intenção de estudar conjuntamente os textos, em seguida, discuti-los com os demais colegas. Muitos outros métodos também são usados para que possamos construir novos saberes acerca do assunto (ACADÊMICO 18).

O conteúdo abordado durante a matéria é permanentemente acompanhado por livros ou subseções de textos, filmes, vídeos, debates em sala de aula, atividades em grupo e até júris simulados. Esta é uma das atividades interativas. Isso chamou minha atenção. Essas atividades nos deixam felizes e me fazem pensar em como estar com futuros alunos (ACADÊMICO 13).

As acadêmicas evidenciaram que o sentido da aprendizagem possui relação com o mundo real, onde uma certa prática se localiza, uma vez que é nessa prática que advém novos modos de pensamento e ação. Assim sendo, a composição estrutural de uma prática pedagógica pautada no diálogo, que objetiva o desenvolvimento de um processo formativo 
emancipatório, encontra efetividade no ensino, na relação entre docente e discentes. Conforme Giancaterino (2018), o foco do processo encaminha-se à práxis social e a questão principal pode ser encontrada no diálogo epistêmico entre entendimento e transformação.

O tópico com menos pontuação foi 'Como examinar e compreender uma produção textual de didática'. Os resultados apresentados relativos a este item denotam que a aprendizagem é um processo que possui relações com o modo pelo qual cada licenciando assimila os saberes, construindo novos a partir deles. Os suportes textuais lidos e debatidos durante a matéria foram abordados de maneira diferenciada, principalmente na relação interativa entre os estudantes, e destes com a professora, tentando concretizar novos saberes partindo de atividades incentivadoras e das práticas experienciadas, pelos acadêmicos, nas instituições escolares do ensino básico. Isto é comprovado no momento em que a acadêmica assevera que: "para realizar os estudos dos textos sugeridos pela professora, pudemos aprender outras formas de estudo, como a Roda de Conversa" (ACADÊMICO 21). Reputamos, com isso, que examinar e compreender produções textuais demanda um grau de saber de maior profundidade, à vista disso, configura-se como um processo que permanece em elaboração pelo licenciando durante sua aprendizagem. Essa acadêmica menciona que: "Não tenho receio em dizer que no começo da disciplina pairou uma confusão em minha mente e, por conta disso, não conseguia relacionar as ideias, no entanto, com o transcurso do semestre, essas ideias começaram a ganhar significado, e percebi como as atividades do professor necessitam da Didática" (ACADÊMICO 09).

\section{Considerações finais}

Com base no exame sistemático das informações coletadas na investigação e nas análises reflexivas produzidas mediante o desenvolvimento desse trabalho científico, alargamos nosso entendimento sobre a disciplina de Didática, enquanto um dos elementos presentes no currículo escolar destinado ao processo formativo da prática do professor. Sua colaboração na formação do futuro profissional da Pedagogia representa um dos fundamentos que constituem a docência, especialmente no que se refere à formação inicial do professor. A Didática abrange dimensões políticas, econômicas, históricas e sociais, revelando sua nãoimparcialidade e as preferências político-ideológicas espelhadas na função do professor, agente político desse processo. Em outros termos, as decisões que o docente tomará, ora ministrando uma disciplina simplesmente técnica ou uma Didática pautada na criticidade, 
presume um determinado entendimento da função do professor e seu desempenho profissional, localizado em uma circunstância cultural, política e social.

Na possibilidade de lançar como proposta uma Didática crítica, a matéria Didática I foi estruturada baseada na Sistematização Coletiva do Conhecimento, procedimento metodológico que leva em consideração a construção do saber segundo um determinado contexto social e que compreende o docente enquanto aquele que tem a capacidade de sustentar um pensamento crítico sobre sua área de atuação profissional, conduzindo-o, na relação com os outros e com a sociedade, à problematização e entendimento de certa circunstância alicerçado em suas descobertas.

Ao participarem efetivamente do processo didático-pedagógico da disciplina, os acadêmicos aumentaram sua autonomia no direcionamento de seu aprendizado; apontaram e descreveram as problemáticas do contexto escolar, procurando respostas para esses impasses partindo do arcabouço teórico que sustenta sua compreensão; aumentaram o entendimento de conjunturas da prática do professor como um todo; amparados nesse entendimento, eles elaboraram propostas de intervenção nessa conjuntura.

Ao examinar os registros da autoavaliação dos licenciandos, argumentamos que a matéria Didática I beneficiou uma percepção metodológica que oferece aos acadêmicos um entendimento das circunstâncias educativas das escolas, assim como seus antagonismos. Essa conduta arquitetada pelo sujeito em sua individualidade, aqui, os acadêmicos do curso de Pedagogia, colaborou para a conscientização através de ações reflexivas realizadas na prática.

Em face dos resultados apresentados durante este trabalho, asseveramos que a disciplina Didática I colabora substancialmente para o processo formativo dos licenciandos, promovendo práticas reflexivas que os auxiliam no desenvolvimento de um entendimento educacional, pautadas na prática social problematizada e nas experiências de vida dos partícipes da escola, docentes e discentes. O envolvimento participativo dos acadêmicos nessa disciplina deixa claro o comprometimento e a coragem que os grupos assumem, salientando que na relação entre professora e acadêmicos a interação dialógica é exequível, a partilha mútua, a afetividade, o espírito criativo, entre outros elementos que ratificam o processo pedagógico, mediado por uma prática destinada ao entendimento de que os conflitos concebidos nos antagonismos da sociedade podem se configurar como objeto de investigação sistemática para uma ressignificação da realidade sob o ponto de vista da emancipação. Assim sendo, o procedimento que especifica a prática de qualquer educador influencia diretamente no processo formativo que este proporciona, isto é, não aprendemos apenas conteúdos da 
matriz curricular, mas existem assuntos e aprendizados subjacentes, até mesmo nos modos do respeito às diferenças.

\section{REFERÊNCIAS}

ALARCÃO, I. Contribuição da didática para a formação de professores: reflexões sobre o seu ensino. In: PIMENTA, S (Org.). Didática e formação de professores: percursos e perspectivas no Brasil e em Portugal. São Paulo, Brasil: Cortez Editora, 2015. p. 159-190.

ALARCÃO, I. Reflexões críticas sobre o pensamento de D. Schön e os programas de formação de professores. In: ALARCÃO, I. (Org.). Formação reflexiva de professores: estratégias de supervisão. Porto: Porto, 2016.

CANDAU, V. M. (Org.). Rumo à nova didática. 24. ed. Petrópolis, RJ: Vozes, 2014.

GIANCATERINO, R. Escola, professor, aluno: os participantes do processo educacional. São Paulo: Madras, 2018.

LIBÂNEO, J. C. Didática. 2. ed. São Paulo, SP: Cortez, 2013.

MANIESI, P. S. Sistematização coletiva do conhecimento como alternativa metodológica para o ensino de física do ensino médio. In: ENDIPE - DIDÁTICA E PRÁTICA DE ENSINO NO CONTEXTO POLÍTICO CONTEMPORÂNEO: CENAS DA EDUCAÇÃO BRASILEIRA, 18., 2016, Cuiabá. Anais [...] Cuiabá, MT: Universidade Federal do mato Grosso, 2016. p. 5386-5390. Disponível em:

https://www.ufmt.br/endipe2016/downloads/233_10180_38086.pdf.Acessado em: 25 de jun. de 2020.

MARIN, A. J. A disciplina didática na formação de professores: conhecimentos, saberes e mediação didática. In: D’ÁVILA, C.; MARIN, A. J.; FRANCO, M. A. S.; FERREIRA, L. G. (Org.). Didática: saberes estruturantes e formação de professores. Salvador: EDUFBA, 2019.

MEDEIROS, E. A.; AGUIAR, A. L. O. Formação inicial de professores da educação básica em licenciaturas de universidades públicas do Rio Grande do Norte: estudo de currículos e suas matrizes curriculares. RIAEE - Revista Ibero-Americana de Estudos em Educação, Araraquara, v. 13, n. 03, p. 1028-1049, jul./set. 2018. Disponível em:

https://periodicos.fclar.unesp.br/iberoamericana/article/view/10975. Acessado em: 24 de agosto de 2020.

MONFREDINI, I.; MAXIMIANO, G. F.; LOTFI, M. C. O deserto da formação inicial nas licenciaturas e alguns oásis. Jundiaí, SP: Paco, 2013. 


\section{Como referenciar este artigo}

GHEDIN, E. L.; MACIEL, C. C. M.; SILVA, A. M. Didática e formação inicial do professor: desafios e perspectivas na visão dos acadêmicos do curso de Pedagogia de uma Instituição de Ensino Superior (IES) do município de Parintins-AM. Revista Ibero-Americana de Estudos em Educação, Araraquara, v. 16, n. esp. 1, p. 881-895, mar. 2021. e-ISSN: 1982-5587. DOI: https://doi.org/10.21723/riaee.v16iEsp.1.14923

Submissão em: $20 / 06 / 2020$

Revisões requeridas em: 16/09/2020

Aceito em: 03/11/2020

Publicado em: 01/03/2021 